\title{
Nuts, bolts and short-chain fatty acids
}

I recall precisely two lectures on nutrition in medical school. True, we heard physiology lectures on shortchain fatty acids, and our biochemistry professors encouraged us to remember the structures of the amino acids, but just how these things related to what a person should eat remained largely indecipherable. One was left with the impression nutrition didn't matter all that much. Or if it did, it was common sense stuff we knew already: Eat your vegetables; lay off the red meat, fat and salt.

It seems my medical education was not unusual. As early as 1966, Robert Shank complained in the pages of the American Journal of Public Health ${ }^{1}$ that "there is inadequate recognition, support, and attention given" to nutrition in medical schools. Fast-forward nearly 50 years, and it seems little has been done to fill the hole. A recent survey of Canadian medical students ${ }^{2}$ revealed that, while they felt comfortable advising patients about basic nutrition and disease prevention, they were uncomfortable discussing the role of nutrition in disease treatment and with finding credible sources of nutrition information. Nearly 90 per cent felt they needed more nutrition education during medical school. So why has nothing changed?

Lead author of the study, University of Alberta gastroenterologist Leah Gramlich is blunt in her answer to that question. "There's no money in being clever about nutrition," she told me. "Everybody owns it. There are no drugs, no scalpels." There is no money for big clinical trials or research programs because few stand to gain.

Gramlich says her experience of nutrition education during her training was much the same as mine: she received next to none. After medical school, she did a residency in internal medicine and then a fellowship in gastroenterology, but learned that even in a field dealing exclusively with the digestive tract, discussion of nutrition was limited. When she told one of her preceptors she was interested in doing a nutrition fellowship at Har- vard, his response was an astounding "What for?"

"Patients believe their doctor knows about nutrition. But you poll doctors, and they'll tell you they don't know. Medical schools say they do nutrition education, but they're just yanking your chain."

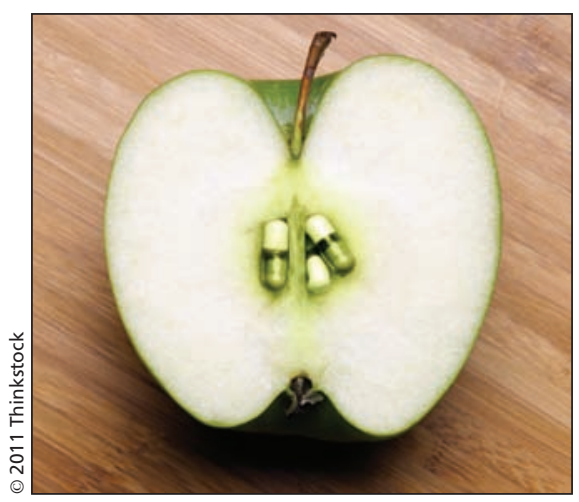

On an otherwise pleasant summer day, I reached into my mailbox to find a flyer from McDonald's $₫$. It offered a coupon for two Big Mac® sandwiches, two medium World Famous Fries ${ }^{\mathrm{TM}}$, and two medium soft drinks, all for $\$ 8.99$. According to McDonald's $®$ online Nutrition Calculator, each meal packed 1120 calories, three-quarters of a day's recommended intake of fat, and half the recommended daily intake each of sodium and carbohydrates. How ironic, I thought, that it should appear alongside my own copy of DietDeck $®$.

The invention of Ottawa, Ontario family doctor Sonja Wicklum, DietDeck® is an example of how one physician has bucked the trend and made nutrition central to her daily practice. Similar to Richard Simmons' Deal-a-Meal, Wicklum's series of cards tracks calories, fat, protein and carbohydrates. The front of each card depicts a specific food group, while the back provides examples of servings with an equivalent number of calories. Pluck a "Protein" card (100 calories), for example, and you'll find three-quarters of a cup of beans, two ounces of cheese, or four tablespoons of nuts. As they're used, cards are moved to the "Eaten" side of the wallet. It's all gloss and italics and watercolour, and retails for about 20 bucks.

Wicklum works at the Ottawa Civic Hospital now, but she developed the idea for the cards during the 1990s, when she was living and working on an Indian reservation in Montana. "I was fairly rural, and I became the go-to person for diabetes and obesity." For a family doctor with a full waiting room, nutrition education was time consuming; she needed something she could give patients to take away and study on their own time, so she designed it. She estimates there are now 50000 decks in circulation.

Like Gramlich and me, Wicklum describes her nutritional education during medical school as "poor to none." As a result, she feels many doctors oversimplify weight issues and are too judgmental. That, she feels, leads to neglect of hospital food budgets, for which patients pay the price. "A great example: A friend of mine had a myocardial infarction and had a stent put in at midnight. I saw him at noon the next day and for lunch he had been given a plate of mac and cheese with a sweet fruit square for dessert!"

I start work as a family doctor in a couple of months, and there's no question that diet-related illness will be my ahem — bread and butter. If I'm to help my patients, I'm going to have to start my own food curriculum from scratch.

\section{Monica Kidd MD}

Resident

St. John's, NL

\section{References}

1. Shank RE. Correlation of nutrition education for public health. II. Nutrition education in school of medicine. Am J Public Health Nations Health 1966;56:929-33

2. Gramlich LM, Olstad DL, Nasser R, et al. Medical students' perceptions of nutrition education in Canadian universities. Appl Physiol Nutr Metab 2010;35:336-43

\section{CMAJ 2011. DOI:10.1503/cmaj.110815}

Do you have an opinion about this article? Post your views at www.cmaj.ca. Potential Salon contributors are welcome to send a query to salon@ cmaj.ca. 